\title{
Monitoring and Controlling of Soil Relative Humidity using Labview
}

\author{
Syambabu Vadlamudi, B.Chinnarao, N.Vanitha
}

\begin{abstract}
The content here gives about the technique which is incorporated to monitor the moisture content in the soil and it enables agriculturalists feasibility of humidity measurement. According to this moisture control sensor circuit, it can observe the corresponding relative humidity and water the plants automatically by observing the conditions using LabVIEW system and myDAQ. The sensed signal from the sensor is interfaced to a LabVIEW loaded PC which acquires the signal as a voltage. With the help of counter pin, a submersible pump turns $\mathrm{ON}$ and $\mathrm{OFF}$ automatically to water the plants based on soils condition. Farmer can vary the time limit. When the time limit exceeds, he can view the LEDs and buzzer is in $\mathrm{ON}$ state. It is applicable in agriculture lands, land irrigation, simple sensors for gardeners.
\end{abstract}

Keywords : Buzzer, DC pump motor, LabVIEW, Motor Driver, myDAQ, Soil Moisture Sensor.

\section{INTRODUCTION}

Automatic control of water plants and manually based on relative humidity of soil by controlling the water pump for eliminating excessive flow of water, hence water is used to a significant extent. Of all the normal modes of measurement and analysis, it is very unique to use LabVIEW as it is a grooming software in the field of Instrumentation and controls Engineering. It can also facilitates engineers to work in single platform with infinite possibilities along with a sophisticated control system. In most of the cultivating estates in semi-arid regions, effective crop protection methods and irrigation management is the major requisite. So we are sensing the relative humidity of soil using soil moisture sensor and controlling the pump motor by using myDAQ control pin which is more secure method to use in the field. The sensed value from soil moisture sensor is more, then the motor will run with a high speed. If soil is getting wet then the speed of the motor will reduce[1].Also controlling it manually by giving the time limit. If the limit exceeds then the buzzer will be ON and LED will be high which indicates the owner about the time that the limit

Revised Manuscript Received on March 28, 2020.

* Correspondence Author

Syambabu Vadlamudi*, Department of Electronics and Communication Engineering, MLR Institute of Technology, Hyderabad, India.

B.Chinnarao, Department of Electronics and Communication Engineering, MLR Institute of Technology, Hyderabad, India.

N.Vanitha, Department of Electronics and Communication Engineering, MLR Institute of Technology, Hyderabad, India.

(C) The Authors. Published by Blue Eyes Intelligence Engineering and Sciences Publication (BEIESP). This is an open access article under the CC BY-NC-ND license (http://creativecommons.org/licenses/by-nc-nd/4.0/) exceed.

\section{PROPOSED APPRAOCH}

\section{A. LabView}

LabVIEW, the Laboratory Virtual Instrumentation Engineering Workbench was a good platform, is a visual programming language currently under development from National Instruments. This visual programming language is named "G" . Original version of this is released for the Apple Macintosh in 1986, mainly used in data collection , control of instrument work, and industrial which works on a plenty of platforms like Windows, various operating systems like UNIX, Linux, and Mac OS X. Version Lab View 2011 is the latest version of Lab View. The code files provided with the extension ".vi" are going to execute in LabVIEW, which is abbreviated from the word "Virtual Instrument". Additional Add-ons and Toolkits are also offered in the LabVIEW.

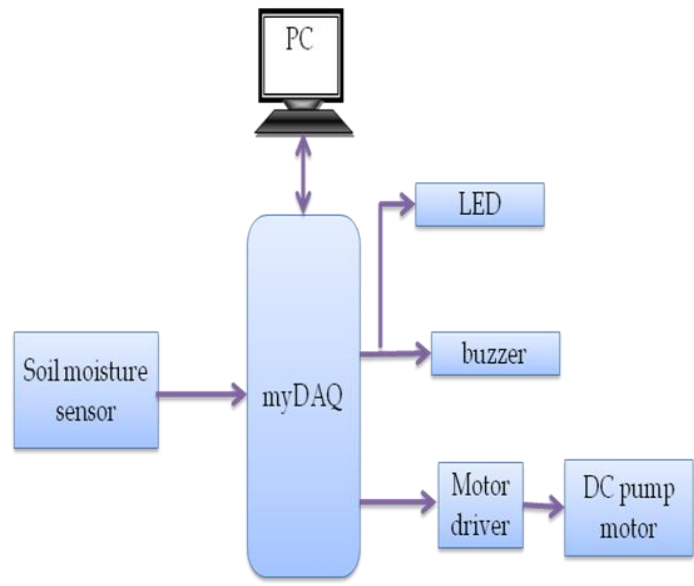

Fig.1: Block diagram of soil moisture sensing

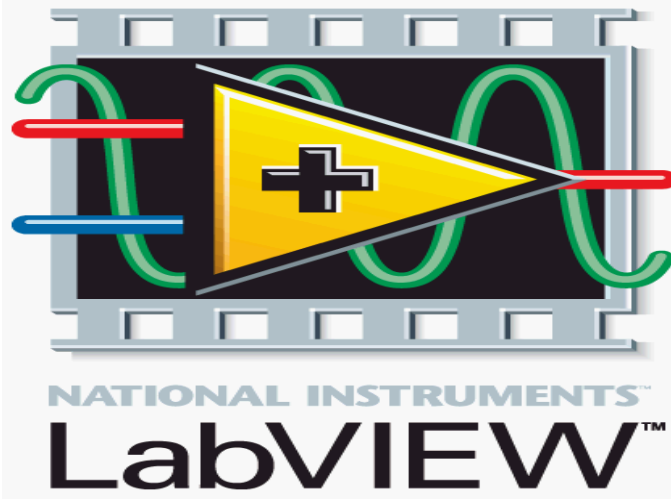

Fig.2: LabVIEW icon

Published By:

Blue Eyes Intelligence Engineering

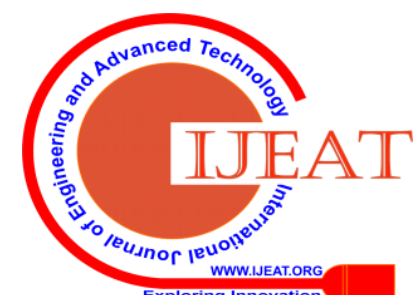




\section{Monitoring and Controlling of Soil Relative Humidity using Labview}

\section{B. Dataflow Programming:}

Dataflow programming language is the programming language used in Laboratory Virtual Instrumentation Engineering Workbench, also referred to as "G". The structure of a graphical block diagram on which the programmer connects different functions determines the execution and nodes by connecting or drawing wires. The nodes which are available with input data can be executed which are connected through the wires."G" can be executed parallelly, since it has multiple nodes to execute. The The built-in scheduler exploits the multiprocessing and multiple threading hardware, which multiplexes multiple Operating Systems threads over the nodes ready for completion [2].

\section{Graphical Programming:}

Laboratory Virtual Instrumentation Engineering Workbench helps the creates the user interface to the development cycle. It has programs and subroutines which are called as virtual instruments. It has multiple components for the development of a program. They are i) Block Diagram, ii) a front panel, iii) a control panel. For allowing an operator to input data into or for the extraction of data from a running virtual instrument, controls and indicators of front panel are used. The front panel also serves as a programmatic interface. Later having the front panel as a user interface, virtual machine can run as the program when dropped as a node onto the block diagram. Connector pane is used to define the inputs and outputs for the given node using front panel.

\section{MyDAQ:}

National instrument's my DAQ is a cost effective mobile data acquisition device, it uses the NI Lab VIEW software instruments, it allowing to measure and analyze the real world signals working. National Instruments's my DAQ is work for searching electronics and takes sensor measurements. Combine with NI Lab VIEW to PC,it can observe and process acquired the signals and control the processes anytime[2]. National Instrument's my DAQ provides the analog input and analog output (AIO), digital input and output (DIO), audio, power supplies, and digital Multi Meter (DMM) functions in a compact USB device. The following figure 3 illustrates myDAQ

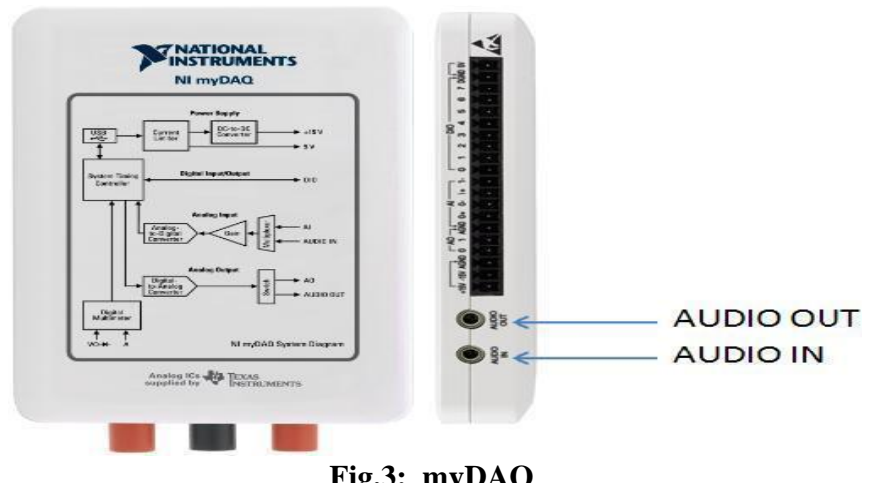

Fig.3: myDAQ

\section{E. LabVIEW Block Diagram}

Firstly ,to install LabVIEW software in your PC/laptop. And are working with myDAQ, so I want to install myDAQ drivers also in your PC/laptop. When open LabVIEW, will get a window known as getting started window. In that window, from menu bar select new VI. Then two windows known as front panel and block diagram can be seen. In front panel we can select controls and indicators from control palette. In block diagram implement our logic by using different kind of icons from function palette. For our project, first task is to control DC pump motor by using control pin in myDAQ. To control the motor, firstly we have to acquire signal from soil moisture sensor.

The soil moisture sensor will give us value in voltage. If the soil is in dry condition, then the sensor will give us maximum voltage that is $5 \mathrm{~V}$. At this situation the pump should rotate with high speed. The soil is getting wet then the voltage value will decrease. If the voltage decreases, the speed of the motor also gets slow. The motor can be controlled by duty cycle value. This duty cycle value will ranges from 0.01 to 0.89 . So, we have to calibrate acquire signal value from soil moisture sensor as the above range.

For sake of that range, we have to divide the value getting from soil moisture sensor with 5.6 to get exact range. This value is given to the duty cycle. It will control the speed of the motor. When the motor is running then we have to check the time limit given by the owner. Until the time limit not exceeds, the LED will be in OFF state and buzzer will be low. When the limit exceeds, then the buzzer will be high and LED will be in ON state. The time limit will be in seconds, minutes or hours and it can be selected by using Enumerated number.

Check the limit by using a tick count. Tick count gives us system time in mille seconds. To divide the value from tick count with 1000 to get the time in seconds. For one minute we have only 60 seconds. But the tick count is giving value up to 1000 seconds. The following figure illustrates the code of our program

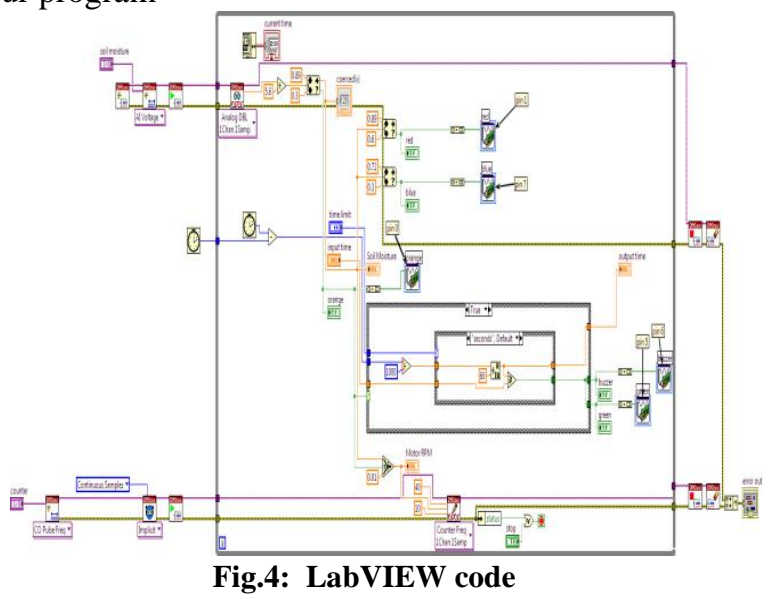

Fig.4: LabVIEW code

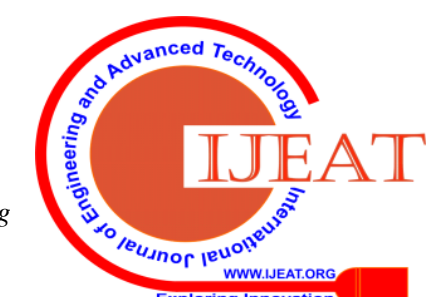




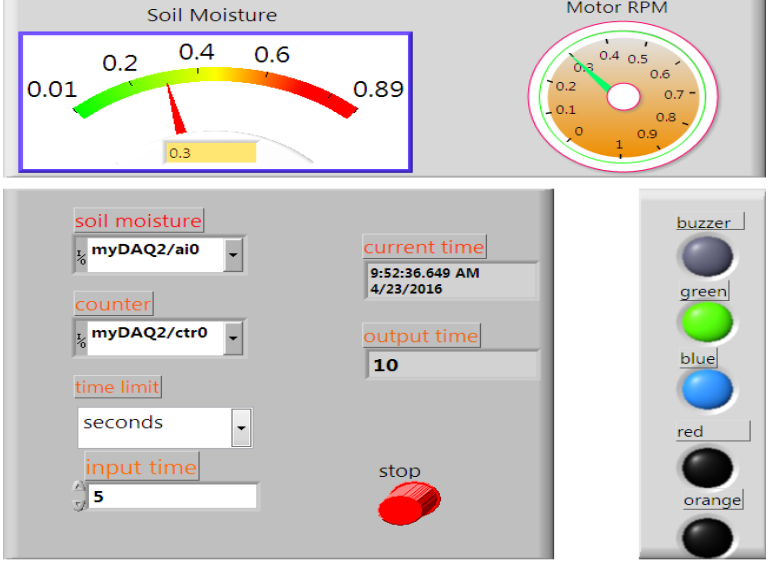

Fig.5: Result

The above figure illustrates the result of our program. Divide this value with 60 to get the seconds up to 60 . The remainder will give us seconds and quotient will give us time in minutes. Again we have to divide this time in minutes with 60 to get the time in hours. The time in hours will be given by the quotient.[4], We can see the values in numeric indicator. If the time limit exceeds the green LED will be in true state. When pump is ON, orange color will be in ON state to indicate the owner that the pump is ON. When soil is in dry condition, the red LED will get ON. When there will be optimum soil water level then both blue and red led will be ON.[6] The blue LED will be ON state if there is excess wet soil. After this excess wet soil condition the DC pump motor will be in OFF state at the same time orange LED will be in OFF state. To implement this code we used so many icons. The icons description will explain briefly below to get basic idea why to use those icons only.[5].

The value sensed from the soil moisture sensor is 0 to $5 \mathrm{~V}$. If it is sensing $4 \mathrm{~V}$ to $5 \mathrm{~V}$ then the soil is in dry condition. Then the motor will run with high speed. If the value sensing is in range of $3.36 \mathrm{~V}$ to $4 \mathrm{~V}$ then the soil is in optimum condition. At this condition the motor will run with medium speed. If the value sensing is in range of $1.68 \mathrm{~V}$ to $3.36 \mathrm{~V}$ then the soil is in wet condition. At this condition the motor will runs very slow. If the value is less than $1.68 \mathrm{~V}$ then the motor will stop pumping water.[4]

Table 1: the following table illustrates the condition of soil

\begin{tabular}{|l|l|}
\hline \multicolumn{1}{|c|}{ SOIL CONDITION } & RANGE \\
\hline Dry condition & 4 to $4.98 \mathrm{~V}$ \\
\hline Optimum & 3.36 to 4 \\
\hline Wet & $1.68 \mathrm{~V}$ to 3.36 \\
\hline
\end{tabular}

\section{CONCLUSION}

This Paper mainly involves the establishing a design technique of controlling and monitoring of humidity level's in soil using NI LabVIEW. This Provide a comprehensive tools that need to build any measurement or control application can be done in less time comparatively. mainly it helpful for small and medium scale agricultural fields. The designing and execution of soil moisture control using NI LabVIEW is the ideal environment for innovation, discovery, and good results. To overcome complexity in calculating the measurements and controlling the systems on time, the power of NI LabVIEW is combined with the modular, reconfigurable hardware. In future we can also detect the objects in the field using PIR sensor. It can capture the image of the persons or objects in the field. It can manually control the pump by using a keypad at home. We can give an alert voice message to the farmer/ owner about the soil condition.

\section{ACKNOWLEDGMENT}

We are thankful to ECE department for all the support. We are grateful for ECE department faculty for providing the valuable inputs for the development of projects.

\section{REFERENCES}

1. Arutselvi.S, Sarah Maria Louis, rinithi.S. "Monitoring and Control of Relative Humidity in Soil using LabVIEW", International Journal of Engineering Trends and Technology (IJETT), V9(10),497-500 March 2014. ISSN:2231-5381. www.ijettjournal.org. published by seventh sense research group.

2. Dr. E.M. Schwartz, TAs: Xin Guan and Ode Ojowu, "NI myDAQ manual", University of http://mil.ufl.edu/3111/docs/myDAQ/Intro_myDAQ

3. T.Bheema lingaiah, D.Hanumesh Kumar, C.Nagaraja, Solomon Woldetsadik International Journal of Advanced Research in Electrical, Electronics and Instrumentation Engineering(An ISO 3297: 2007 Certified Organization) Vol. 2, Issue 10, December 2013 "Development of Humidity and Temperature Measurement Instrumentation System using LabVIEW"

4. G.Shravan Kumar, Monitoring of relative humidity in soil using LabVIEW, JARDCS, Vol.12,no.8, 2017.

5. Sudip Das1, Biswamoy Pal2 , Partha Das3 , Milan Sasmal4 Prabuddhamoy Ghosh5, Design and Development of Arduino based Automatic Soil Moisture Monitoring System for Optimum use of Water in Agricultural Fields, International Journal of Engineering Research \& Science (IJOER) ISSN: [2395-6992] [Vol-3, Issue-5, May- 2017]

6. Tasneem Khan Shifa, Moisture Sensing Automatic Plant Watering System Using Arduino Uno, American Journal of Engineering Research (AJER) e-ISSN: 2320-0847 p-ISSN : 2320-0936 Volume-7, Issue-7, pp-326-33

\section{AUTHORS PROFILE}

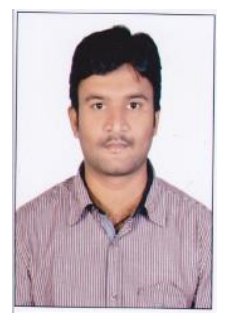

Syambabu Vadlamudi, received his B.Tech., degree in Electronics and Communication Engineering, at JNTU Hyderabad and M.Tech., degree in Digital Electronics and Communications Systems at JNTU Kakinada. His area of interest includes Communication systems, Image processing and Multimedia Security. He has published more than 10 papers in various reputed National, International conferences and Journals. Currently he is working as a Assistant Professor at MLR Institute of Technology, Hyderabad, India.

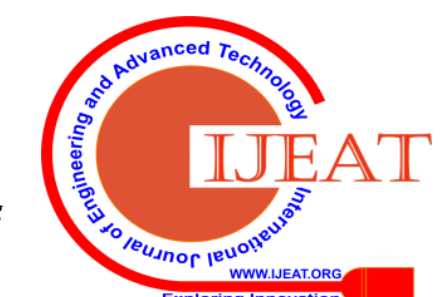

